\title{
Outcomes of intracorporeal versus extracorporeal anastomosis in laparoscopic colectomy surgery
}

\author{
Song I Yang, Seung Hun Lee, Seung Hyun Lee \\ Department of Surgery, Kosin University College of Medicine, Busan, Korea
}

Purpose: The aim of this study is to evaluate the feasibility and safety of intracorporeal anastomosis in laparoscopic colectomy for benign and malignant tumor diseases in actual clinical settings.

Methods: From January 2016 to June 2021, a total of 114 cases were selected for laparoscopic colectomy for benign or malignant tumor diseases. Seventeen cases that underwent simultaneous combined laparoscopic procedures were excluded from the study. The remaining patients were separated into 48 cases in the intracorporeal group and 49 cases in the extracorporeal group. Medical records were reviewed retrospectively.

Results: Patients in the intracorporeal group were older than those in the extracorporeal group (62.6 years vs. 54.9 years, $p=0.001$ ). Body mass index, American Society of Anestheologists physical status classification, comorbidity, smoking, and laparotomy history did not differ significantly between groups. Surgeries for malignancy were performed in $35(72.9 \%)$ and 32 cases $(65.3 \%)$ in the respective intracorporeal and extracorporeal groups. Right hemicolectomy was performed in 39 (81.3\%) and 45 cases (91.8\%) in the intracorporeal and extracorporeal groups, respectively, and postoperative hospital stays were 9.8 and 8.9 days ( $p=0.081)$. Operation time (216.9 minutes vs. 203.5 minutes, $p=0.212)$ and intraoperative blood loss (72.7 mL vs. $75.7 \mathrm{~mL}, p=0.700$ ) were not significantly different. Anastomotic leakage was observed in one case in each group.

Conclusion: In laparoscopic colectomy, intracorporeal anastomosis could be considered as a safe and feasible technique for benign and malignant tumor diseases.

Keywords: Laproscopy, Colorectal surgery, Anastomosis

This is an Open Access article distributed under the terms of the Creative Commons Attribution Non-Commercial License (http:// creativecommons.org/licenses/by-nc/4.0/) which permits unrestricted non-commercial use, distribution, and reproduction in any medium, provided the original work is properly cited.
Received October 30, 2021

Revised 1st November 12, 2021 2nd November 30, 2021

3rd December 6, 2021

4th December 8, 2021

Accepted December 9, 2021

Corresponding author

Seung Hyun Lee

Department of Surgery, Kosin

University College of Medicine, 262

Gamcheon-ro, Seo-gu, Busan 49267,

Korea

Tel: +82-51-990-6462

Fax: +82-51-246-6093

E-mail: gscrslsh@kosinmed.or.kr ORCID:

https://orcid.org/0000-0002-5610-5237
Copyright (C) The Korean Society of Endoscopic and Laparoscopic Surgeons.

\section{INTRODUCTION}

In the field of colorectal surgery, laparoscopic surgery is becoming more popular and is experiencing an expansion in its scope of applications for a variety of benign and malignant tumor diseases [1-5]. With the development of surgical instruments and surgical techniques, a technical approach to a more sophisticated field has become possible. Recently, the applicability and safety of many challenging techniques have been verified through comparative studies.
Among the various advanced laparoscopic surgical techniques, intracorporeal anastomosis is being studied for its applicability and safety. Several studies have shown that intracorporeal anastomosis has advantages such as relatively less invasiveness, faster recovery after surgery, and shorter hospital stays. However, further research and validation are needed [6-15].

The aim of this study is to evaluate the feasibility and safety of intracorporeal anastomosis in laparoscopic colectomy for benign or malignant tumor diseases in actual clinical settings. 


\section{MATERIALS AND METHODS}

Patients who underwent laparoscopic colectomy from January 2016 to June 2021 at Kosin University Gospel Hospital in Busan, Korea were selected. Laparoscopic colectomy operations for benign and malignant diseases were performed by a single surgeon. The exclusion criteria were cases with colon obstruction, bowel perforation, open conversion surgery, or combined operations.

Intracorporeal bowel anastomoses were completed in a sideto-side manner with three linear cutter staplers. One linear cutter stapler was used for the separation of the proximal bowel, typically the ileum. Another linear cutter stapler was used for the separation of the distal bowel, usually the colon. Two small holes were created on each side of the bowel wall, and a third linear cutter stapler was inserted into one hole on each side to perform an anastomosis in a side-to-side, isoperistaltic manner. The remaining small holes were closed with barbed suture material with lambert reinforcement sutures. Mesenteric defects were closed with barbed suture material.

Extracorporeal anastomoses were performed with extracorporeal bowel extraction through a periumbilical small abdominal incision. The anastomoses were completed in a side-to-side or end-to-end manner with a stapled or handsewn technique. For the stapled technique, two small holes were created on each side of the bowel wall before the cutting of the bowel. Each blade of the linear cutter stapler was inserted into two holes on each side to perform an anastomosis in a side-to-side, antiperistaltic manner. With another linear cutter stapler, each side of the bowels was cut, including the hole site. Re-enforcement sutures were undergone on the cutting side of the bowels. Intracorporeally, mesenteric defects were closed with barbed sutures.

According to the anastomotic technique, the patients were divided into intracorporeal and extracorporeal groups. Medical records were reviewed retrospectively for demographics, comorbidity, operation methods, operative time, intraoperative blood loss, postoperative hospital stay, postoperative complications, and pathology results. Operation time was defined as the time from the initial incision to the completion of postsurgical dressing. Operative complications and mortality were defined as those within 30 days of surgery, respectively.

For statistical analysis, SPSS version 17.0 for Windows (SPSS Inc., Chicago, IL, USA) was used. The Student $t$ test was used to compare normally distributed variables. Comparisons between groups of discrete variables were performed using the chi-square or Fisher exact test as appropriate. All $p$ values of $<0.05$ were considered statistically significant.

\section{RESULTS}

A total of 114 patients underwent laparoscopic colectomy for benign or malignant disease. The intracorporeal group involved 63 cases, while the extracorporeal group included 51 cases. In the intracorporeal group, 15 cases were excluded due to the presence of the combined surgeries: six cholecystectomies, two liver resection surgeries, one liver resection surgery with colectomy, three colectomies, one small bowel resection, and two oophorectomies. In the extracorporeal group, two cases that underwent combined cholecystectomy were excluded (Fig. 1).

Demographics are provided in Table 1. The intracorporeal group was older than the extracorporeal group (62.6 years vs. 54.9 years, $p=0.001$ ). Body mass index (BMI), American Society of Anestheologists (ASA) physical status classification, comorbidity, smoking, and previous laparotomy history did not differ significantly between the two groups. Surgeries for malignancy were performed on $35(72.9 \%)$ and 32 patients $(65.3 \%)$ in the respective intracorporeal and extracorporeal groups. In both groups, all malignant cases were diagnosed as adenocarcinoma, except one malignant lymphoma in the intracorporeal group. Right hemicolectomy was performed in 39 (81.3\%) and 45 cases (91.8\%), respectively. In the intracorporeal group, other surgeries

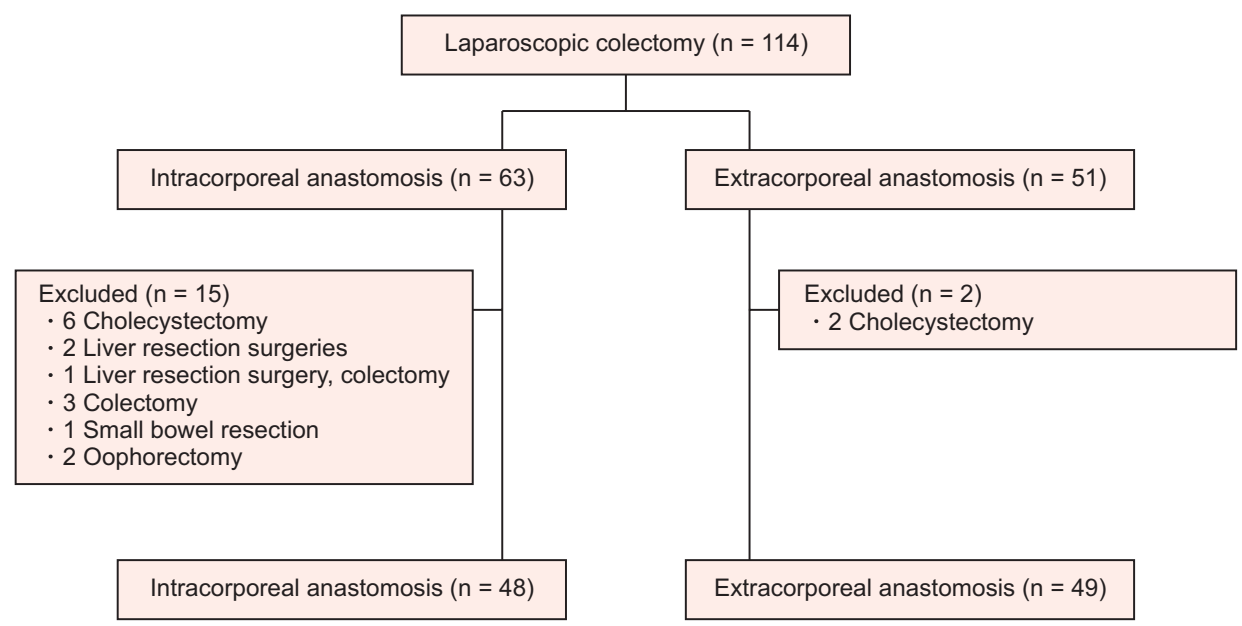

Fig. 1. Flowchart of patient enrollment. 
Table 1. Demographics of patients

\begin{tabular}{|c|c|c|c|}
\hline Characteristic & Intracorporeal & Extracorporeal & $p$ value \\
\hline No. of patients & 48 & 49 & \\
\hline Age (yr) & $62.6 \pm 12.1(25-85)$ & $54.9 \pm 19.5(15-85)$ & 0.001 \\
\hline Sex & & & 0.105 \\
\hline Male & $21(43.8)$ & $30(61.2)$ & \\
\hline Female & $27(56.2)$ & $19(38.8)$ & \\
\hline Body mass index $\left(\mathrm{kg} / \mathrm{m}^{2}\right)$ & $23.6 \pm 3.5(18.6-33.7)$ & $23.0 \pm 4.0(14.8-33.5)$ & 0.583 \\
\hline ASA PS classification & & & 0.078 \\
\hline $1-\|$ & $35(72.9)$ & $43(87.8)$ & \\
\hline$\geq \| 11$ & $13(27.1)$ & $6(12.2)$ & \\
\hline \multicolumn{4}{|l|}{ Comorbidity } \\
\hline Cardiovascular disease & $10(20.8)$ & $8(16.3)$ & 0.606 \\
\hline Diabetes mellitus & $13(27.1)$ & $7(14.3)$ & 0.139 \\
\hline Smoking & & & 0.544 \\
\hline Yes & $11(22.9)$ & $14(28.6)$ & \\
\hline No & $37(77.1)$ & $35(71.4)$ & \\
\hline Previous laparotomy & & & $>0.999$ \\
\hline Yes & $10(20.8)$ & $11(22.4)$ & \\
\hline No & $38(79.2)$ & $38(77.6)$ & \\
\hline Diagnosis & & & 0.511 \\
\hline Malignancy & $35(72.9)$ & $32(65.3)$ & \\
\hline Benign & $13(27.1)$ & $17(34.7)$ & \\
\hline Operation & & & 0.147 \\
\hline Right hemicolectomy & $39(81.3)$ & $45(91.8)$ & \\
\hline Others ${ }^{a)}$ & $9(18.8)$ & $4(8.2)$ & \\
\hline T stage $e^{b)}$ & & & 0.283 \\
\hline T0-T2 & $12(35.4)$ & $7(21.9)$ & \\
\hline T3-T4 & $22(64.7)$ & $25(78.1)$ & \\
\hline N stage & & & 0.460 \\
\hline NO & $14(41.2)$ & $17(53.1)$ & \\
\hline $\mathrm{N} 1-\mathrm{N} 2$ & $20(58.8)$ & $15(46.9)$ & \\
\hline
\end{tabular}

Values are presented as number only, mean \pm standard deviation (range), or number (\%).

ASA, American Society of Anestheologists; PS, physical status.

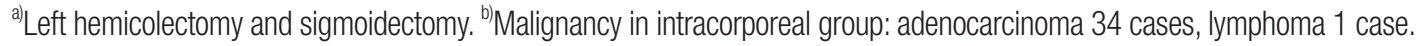

included one transverse colectomy, five left hemicolectomies, and three sigmoidectomies. In the extracorporeal group, all four other surgeries were left hemicolectomies. In the cases of other surgeries, anastomosis was undergone with a linear stapler. A circular stapler was not used.

Operative outcomes and postoperative complications are included in Tables 2 and 3. The intracorporeal group had a longer postoperative hospital stay; however, this was not statistically significant ( 9.8 days and 8.9 days, $p=0.081$ ). Operation time $(216.9$ minutes vs. 203.5 minutes, $p=0.212$ ) and intraoperative blood loss (72.7 mL vs. $75.7 \mathrm{~mL}, p=0.700)$ were not significantly different. Anastomotic leakage was seen in one case in each group. In both groups, two cases of anastomotic leakage were managed with reoperation. There was no case of wound infection or ileus. 
Table 2. Operative outcomes

\begin{tabular}{lccc|}
\hline \multicolumn{1}{c}{ Outcome } & Intracorporeal $(\mathrm{n}=48)$ & Extracorporeal $(\mathrm{n}=49)$ & $p$ value \\
\hline Postoperative hospital stay (day) & $9.8 \pm 8.9(5-54)$ & $8.9 \pm 4.2(6-21)$ & 0.081 \\
\hline Operative time $(\mathrm{min})$ & $216.9 \pm 102.1(130.0-655.0)$ & $203.5 \pm 50.5(120.0-380.0)$ & 0.212 \\
\hline Blood loss (mL) & $72.7 \pm 74.3(50-400)$ & $75.7 \pm 78.7(50-500)$ & 0.700 \\
\hline Sampled lymph node & $21.3 \pm 7.7(9-46)$ & $22.5 \pm 10.4(3-64)$ & 0.471 \\
\hline
\end{tabular}

Values are presented as mean \pm standard deviation (range).

Table 3. Postoperative complications

\begin{tabular}{|lccc|}
\hline \multicolumn{1}{|c}{ Complication } & Intracorporeal $(\mathrm{n}=48)$ & Extracorporeal $(\mathrm{n}=49)$ & $p$ value \\
\hline Total & $2(4.2)$ & $4(8.2)$ & 0.678 \\
\hline Anastomotic leakage & 1 & 1 & \\
\hline Wound infection & 0 & 0 \\
\hline lleus & 0 & 0 \\
\hline Chyle leakage & 0 & 1 \\
\hline Bladder dysfunction & 0 & 1 \\
\hline Colitis & 0 & 1 \\
\hline Death & $1^{\text {a) }}$ & 0 \\
\hline
\end{tabular}

Values are presented number (\%) or number only.

${ }^{a}$ Death due to heart failure, in which case with aortic stenosis, hypertension, diabetes mellitus, and end-stage renal dysfunction.

The one postoperative mortality case in the intracorporeal group was due to heart failure with aortic stenosis, hypertension, diabetes mellitus, and end-stage renal dysfunction.

\section{DISCUSSION}

In the field of laparoscopic colorectal surgery, especially for rightsided colon disease, intestinal anastomosis has been performed outside the abdominal cavity as an extracorporeal anastomosis with a manual or stapled technique. The configurations of anastomoses, such as end-to-end, end-to-side/side-to-end, or side-toside manner, are variable. Until recently, extracorporeal anastomosis has been performed predominantly due to its technical familiarity to surgeons, resembling conventional open surgery.

However, for extracorporeal anastomosis, more extensive mesenteric dissection is required to extract the two bowel ends through the assistant incision, especially in obese patients with thick abdominal walls and thick mesenteries [6]. Sometimes, the surgeon addresses short bowel length through extracorporeal manipulation and unexpected mesenteric bleeding with excessive traction through the extraction site. However, the risk of mesenteric twisting is higher after extracorporeal anastomosis [7]. In our institution, extracorporeal anastomosis was the preferred technique in most cases, especially for ileocolic anastomosis. We frequently encountered the same situations, such as longer surgical incisions related to thick abdominal walls, bulky mesentery, unexpected mesenteric bleeding, and mesenteric twisting during extracorporeal anastomosis. To improve these problems, intracorporeal anastomosis was undergone for trial purposes in 63 cases. In this study, the mean BMI did not differ between groups $\left(23.6 \mathrm{~kg} / \mathrm{m}^{2}\right.$ vs. $\left.23.0 \mathrm{~kg} / \mathrm{m}^{2}, p=0.583\right)$. However, the obese patients (with BMI of $>30 \mathrm{~kg} / \mathrm{m}^{2}$ ) were included more in the intracorporeal anastomosis group (four cases vs. one case). In the four obese patients, thick abdominal walls and bulky mesenteries were not troublesome factors during the operation. There was no case of mesenteric twisting. To perform intracorporeal anastomosis, surgeons have to overcome many challenges, such as laparoscopic suturing, in the field of laparoscopic techniques. With the development of surgical instruments and surgical techniques, a technical approach to a more sophisticated field has become possible. Recently, laparoscopic intracorporeal intestinal anastomosis has been attempted to determine feasibility and safety.

Advantages such as smaller surgical incisions, lower conversion rates, earlier bowel function recoveries, and shorter hospital stays have been demonstrated. Expected disadvantages include longer operative times associated with technical challenges and higher complication risks such as surgical site infections or anastomotic leakages. In addition, surgeons have to be concerned about the 
intraabdominal stool contamination management during the creation of a hole in the bowel for intracorporeal anastomosis. However, the present study did not demonstrate the benefits of intracorporeal anastomosis, such as smaller incisions and earlier bowel function recoveries. There was no open conversion case. The postoperative hospital stays (9.8 days vs. 8.9 days, $p=0.081$ ) and blood loss $(72.7 \mathrm{~mL}$ vs. $75.7 \mathrm{~mL}, p=0.700)$ were not significantly different in both groups. We expected a longer operation time and a higher rate of anastomotic leakage in the intracorporeal anastomosis group. However, both the anastomotic leakage rate and operation time (216.9 minutes vs. 203.5 minutes, $p=0.212$ ) were not different in this study.

Raftopoulos et al. [6] analyzed the results of 54 cases of intracorporeal anastomosis, assuming that the length of the incision and conversion rate would be reduced in patients, particularly those with high obesity. In that study, the incision was small (mean, $4 \mathrm{~cm}$; range, 3-8 cm) and cosmetically satisfactory. There was no conversion to open surgery. However, there was no difference in the results of surgery according to the degree of obesity. Grams et al. [8] reported the results of a comparative study of intracorporeal anastomosis in 54 patients and extracorporeal anastomosis in 51 patients who underwent ileocolic resection (66 cases), right hemicolectomy (29 cases), left hemicolectomy (nine cases), and subtotal colectomy (one case). In that study, operation time was significantly longer for intracorporeal anastomosis, though estimated blood loss, postoperative narcotic use, length of hospital stay, and complications were lower.

Allaix et al. [16] conducted a double-blind, randomized controlled trial of 140 laparoscopic right hemicolectomies, comparing the outcomes of intracorporeal and extracorporeal anastomoses. The trial demonstrated a quicker recovery of bowel function after intracorporeal anastomosis. The operation time, length of incision, 30-day morbidity, and length of hospital stay were not significantly different between groups.

Bollo et al. [17] conducted another randomized controlled trial of 140 laparoscopic right hemicolectomy patients. The trial showed that the length of the incision was shorter with the intracorporeal anastomosis technique (median of $6.7 \mathrm{~cm}$ vs. $8.7 \mathrm{~cm}, p<$ 0.001 ), as was the rate of recovery of bowel function. The study exhibited good results in postoperative pain management and complications. On the other hand, the operation time was rather long (median of 149 minutes vs. 123 minutes, $p<0.001$ ).

There are also several systemic reviews and meta-analysis studies [18-23]. Aiolfi et al. [23] published the results of a metaanalysis of 23 studies. The analysis reported that the intracorporeal anastomosis technique improved bowel function recovery, as measured by gas excretion and diet control; shortened hospital stays; and lowered the rate of surgical site infections and postoperative complications.

Although many studies have reported improvement in out- comes after laparoscopic intracorporeal anastomosis in colorectal surgery, extracorporeal anastomosis is more common in the operating room. This might be because intracorporeal anastomosis requires a skilled laparoscopic suture technique and a slightly longer operation time.

In this study, the intracorporeal anastomosis technique was attempted surgically due to technical difficulties with extracorporeal management, such as shortness of extracted bowel length to manipulate and unexpected mesenteric bleeding during the bowel extraction, especially in obese patients.

To reduce surgical site infection, all patients in this study underwent mechanical bowel preparation with oral antibiotics. Because we did not use laparoscopic bowel clamps, we experienced minor stool leakage during a procedure making holes in the bowel wall and manipulation of linear cutter staplers. To minimize contamination of minor stool leakage, we used betadine gauze, which was put around the area where anastomotic procedure was performed. Surgical site infection was not observed in the intracorporeal anastomosis group.

The intracorporeal anastomosis was performed with a total of three linear cutter staplers in isoperistaltic manner. One linear cutter stapler was used for cutting the transverse colon, whereas another linear cutter stapler was used for cutting the terminal ileum. One fixing suture was made between the proximal end of the transverse colon and a 7 to $8-\mathrm{cm}$ proximal point from the distal end of the terminal ileum. After making holes on both sides of the bowels, the third linear cutter stapler for anastomosis was inserted through a 12-mm trocar on the left upper quadrant abdominal site. The remaining small hole in the bowels was closed with a barbed suture. Mesenteric defects were closed in all cases. The specimen was extracted through the periumbilical incision with an extension of the 11-mm trocar wound for the laparoscopic camera.

We expected that intracorporeal anastomosis had some advantage, such as shorter dissection length of the transverse colon and smaller skin incision length while demonstrating technical difficulties resulting in a longer operation time and higher rates of surgical site infection or anastomotic leakage. However, this study did not show any difference in postoperative outcomes between the groups

This study has limitations caused by the retrospective study design with small number of patients and heterogeneous operating procedures

In conclusion, postoperative outcomes are comparable between intracorporeal and extracorporeal anastomosis. In laparoscopic colectomy, intraoperative anastomosis could be considered a safe and feasible technique for benign and malignant tumor diseases. 


\section{NOTES}

\section{Ethical statements}

The current study was performed in accordance with the Declaration of Helsinki. The study protocol was approved by the Institutional Review Board of Kosin University Gospel Hospital, with a waiver of informed consent (No. 2021-07-016).

\section{Authors' contributions}

Conceptualization: Seung Hun L, Seung Hyun L

Data curation: All authors

Formal analysis: All authors

Investigation: Seung Hun L, Seung Hyun L

Methodology: Seung Hun L, Seung Hyun L

Project administration: Seung Hyun L

Visualization: SIY, Seung Hyun L

Writing-original draft: SIY, Seung Hyun L

Writing-review \& editing: SIY, Seung Hyun L

All authors read and approved the final manuscript.

\section{Conflict of interest}

All authors have no conflicts of interest to declare.

\section{Funding/support}

None.

\section{ORCID}

Song I Yang, https://orcid.org/0000-0003-1343-1064

Seung Hun Lee, https://orcid.org/0000-0001-9041-3156

Seung Hyun Lee, https://orcid.org/0000-0002-5610-5237

\section{REFERENCES}

1. Lacy AM, García-Valdecasas JC, Delgado S, et al. Laparoscopy-assisted colectomy versus open colectomy for treatment of non-metastatic colon cancer: a randomised trial. Lancet 2002;359:2224-2229.

2. Guller U, Jain N, Hervey S, Purves H, Pietrobon R. Laparoscopic vs open colectomy: outcomes comparison based on large nationwide databases. Arch Surg 2003;138:1179-1186.

3. Clinical Outcomes of Surgical Therapy Study Group, Nelson H, Sargent DJ, et al. A comparison of laparoscopically assisted and open colectomy for colon cancer. N Engl J Med 2004;350:2050-2059.

4. Veldkamp R, Gholghesaei M, Bonjer HJ, et al. Laparoscopic resection of colon cancer: consensus of the European Association of Endoscopic Surgery (EAES). Surg Endosc 2004;18:1163-1185.
5. Noel JK, Fahrbach K, Estok R, et al. Minimally invasive colorectal resection outcomes: short-term comparison with open procedures. J Am Coll Surg 2007;204:291-307.

6. Raftopoulos I, Courcoulas AP, Blumberg D. Should completely intracorporeal anastomosis be considered in obese patients who undergo laparoscopic colectomy for benign or malignant disease of the colon? Surgery 2006;140:675-683.

7. Hellan M, Anderson C, Pigazzi A. Extracorporeal versus intracorporeal anastomosis for laparoscopic right hemicolectomy. JSLS 2009;13: 312-317.

8. Grams J, Tong W, Greenstein AJ, Salky B. Comparison of intracorporeal versus extracorporeal anastomosis in laparoscopic-assisted hemicolectomy. Surg Endosc 2010;24:1886-1891.

9. Lee KH, Ho J, Akmal Y, Nelson R, Pigazzi A. Short- and long-term outcomes of intracorporeal versus extracorporeal ileocolic anastomosis in laparoscopic right hemicolectomy for colon cancer. Surg Endosc 2013;27:1986-1990.

10. Milone M, Elmore U, Di Salvo E, et al. Intracorporeal versus extracorporeal anastomosis. Results from a multicentre comparative study on 512 right-sided colorectal cancers. Surg Endosc 2015;29:2314-2320.

11. Vergis AS, Steigerwald SN, Bhojani FD, Sullivan PA, Hardy KM. Laparoscopic right hemicolectomy with intracorporeal versus extracorporeal anastamosis: a comparison of short-term outcomes. Can J Surg 2015;58:63-68.

12. Hanna MH, Hwang GS, Phelan MJ, et al. Laparoscopic right hemicolectomy: short- and long-term outcomes of intracorporeal versus extracorporeal anastomosis. Surg Endosc 2016;30:3933-3942.

13. Shapiro R, Keler U, Segev L, Sarna S, Hatib K, Hazzan D. Laparoscopic right hemicolectomy with intracorporeal anastomosis: short- and long-term benefits in comparison with extracorporeal anastomosis. Surg Endosc 2016;30:3823-3829.

14. Vignali A, Bissolati M, De Nardi P, Di Palo S, Staudacher C. Extracorporeal vs. intracorporeal ileocolic stapled anastomoses in laparoscopic right colectomy: an interim analysis of a randomized clinical trial. J Laparoendosc Adv Surg Tech A 2016;26:343-348.

15. Biondi A, Santocchi P, Pennestrì F, Santullo F, D’Ugo D, Persiani R. Totally laparoscopic right colectomy versus laparoscopically assisted right colectomy: a propensity score analysis. Surg Endosc 2017;31: 5275-5282.

16. Allaix ME, Degiuli M, Bonino MA, et al. Intracorporeal or extracorporeal ileocolic anastomosis after laparoscopic right colectomy: a double-blinded randomized controlled trial. Ann Surg 2019;270:762767.

17. Bollo J, Turrado V, Rabal A, et al. Randomized clinical trial of intracorporeal versus extracorporeal anastomosis in laparoscopic right colectomy (IEA trial). Br J Surg 2020;107:364-372.

18. Feroci F, Lenzi E, Garzi A, Vannucchi A, Cantafio S, Scatizzi M. Intracorporeal versus extracorporeal anastomosis after laparoscopic right hemicolectomy for cancer: a systematic review and meta-analysis. Int J Colorectal Dis 2013;28:1177-1186. 
19. Cirocchi R, Trastulli S, Farinella E, et al. Intracorporeal versus extracorporeal anastomosis during laparoscopic right hemicolectomy: systematic review and meta-analysis. Surg Oncol 2013;22:1-13.

20. Wu Q, Jin $\mathrm{C}, \mathrm{Hu} \mathrm{T}$, Wei $\mathrm{M}$, Wang Z. Intracorporeal versus extracorporeal anastomosis in laparoscopic right colectomy: a systematic review and meta-analysis. J Laparoendosc Adv Surg Tech A 2017;27: 348-357.

21. van Oostendorp S, Elfrink A, Borstlap W, et al. Intracorporeal versus extracorporeal anastomosis in right hemicolectomy: a systematic re- view and meta-analysis. Surg Endosc 2017;31:64-77.

22. Emile SH, Elfeki $H$, Shalaby $M$, et al. Intracorporeal versus extracorporeal anastomosis in minimally invasive right colectomy: an updated systematic review and meta-analysis. Tech Coloproctol 2019;23: 1023-1035.

23. Aiolfi A, Bona D, Guerrazzi G, et al. Intracorporeal versus extracorporeal anastomosis in laparoscopic right colectomy: an updated systematic review and cumulative meta-analysis. J Laparoendosc Adv Surg Tech A 2020;30:402-412. 